\title{
DiscuRSOS SOBRE A RELAÇÃo SANEAMENTO-SAÚDE-AMBIENTE NA LEGISLAÇÃO: UMA ANÁLISE DE CONCEITOS E DIRETRIZES
}

\section{DISCOURSES ON SANITATION-HEALTH-ENVIRONMENT RELATIONSHIP IN THE LEGISLATION: AN ANALYSIS OF CONCEPTS AND LINES OF DIRECTION}

\section{CEZARINa Maria Nobre SouZa}

Professora do Centro Federal de Educação Tecnológica do Pará. Doutoranda em Saúde Pública (ENSP/FIOCRUZ). Mestre em Tecnologia Ambiental (UnB). Graduada em Engenharia Sanitária (UFPA)

\section{CARLOS MACHADO DE FREITAS}

Professor e Pesquisador da Escola Nacional de Saúde Pública da Fundação Oswaldo Cruz. Doutor em Saúde Pública (ENSP/FIOCRUZ). Mestre em Engenharia de Produção (UFRJ). Graduado em História (UFF)

\section{Luiz Roberto SANTOS Moraes}

Professor Titular do Departamento de Engenharia Ambiental da Escola Politécnica e do Programa de Pós-Graduação em Engenharia Ambiental Urbana da Universidade Federal da Bahia. PhD em Saúde Ambiental (LSHTM/University of London). Mestre em Engenharia Sanitária (IHE/Delft University of Technology). Engenheiro Civil

(EP/UFBA) e Sanitarista (FSP/USP)

Recebido: 18/10/06 Aceito: 15/08/07

\section{RESUMO}

Foram identificados em textos da legislação brasileira diversos discursos que tratam do conceito de saneamento, de saúde e de ambiente, bem como das práticas exercidas no setor de saneamento. Buscou-se com isso verificar se a percepção que os mesmos revelam sobre tais temas se aproxima de uma visão de prevenção de doenças ou de promoção da saúde. Concluiu-se que, relativamente aos conceitos, há predominância de uma visão preventivista; existência de ambigüidades dentro de uma mesma lei; ocorrência de omissōes. No que tange às práticas, há predominância de discursos promocionais; ambigüidades e omissóes discursivas.

PALAVRAS-CHAVE: Saneamento, ambiente, promoção da saúde, prevenção de doenças, legislação.

\section{INTRODUÇÃO}

A literatura científica consubstanciada basicamente por Stachtchenko e Jenicek (1990), Teixeira (2001), Czeresnia e Freitas (2003) e Lefevre e Lefevre (2004), dentre outros autores, estabelece uma discussão sobre o significado e as bases da promoção da saúde - PS.

Seguindo essa mesma tendência de reflexão crítica, em Souza e Freitas (2006) são propostas as bases teóricas de um saneamento alicerçado na prevenção de doenças e na promoção da saúde.

Dentre outras características, para Souza e Freitas (2006), o saneamento preventivista é uma intervenção de engenharia no ambiente (considerado exclusivamente como espaço físico), voltada para a saúde (compreendida como ausência de doenças), obstaculizando a transmissão de doenças e assegurando a salubridade ambiental.

Como prevenção, o saneamento se preocupa com a articulação institucional para que os sistemas de engenharia funcionem (tenham sustentabilidade), realizando adaptaçôes tecnológicas às características físicas da área alvo, ficando a responsabilidade pelas açôes concentrada exclusivamente nas mãos dos engenheiros e sua equipe de educação ambiental. Percebe a educação sanitária e ambiental como ferramenta para ensinar novos hábitos e costumes à população, cuja participação nos processos decisórios nada mais é do que a chancela às decisōes já tomadas.

Por outro lado, o saneamento como promoção da saúde é uma intervenção multidimensional que se dá no ambiente (considerado em suas dimensôes física, social, econômica, política e cultural), visando à saúde (entendida como qualidade de vida; erradicação da doença pelo combate integral às suas causas e determinantes), por meio da implantação de sistemas de engenharia associada a um conjunto de açōes integradas.

O saneamento promocional está voltado para a sustentabilidade desses sistemas e ações associadas e para sua 
adaptação ao contexto geral onde são executados. Busca a articulação entre instituiçõos e a população com vistas ao fortalecimento da mesma, compartilhando com ela e com outros setores técnicos envolvidos a responsabilidade pelas ações e decisões. Compreende a educação sanitária e ambiental voltada para a promoção do ser humano.

Com base no exposto, o objetivo que se propõe alcançar é analisar, no âmbito da legislação, discursos existentes sobre os conceitos de saneamento, saúde e ambiente, assim como sobre as práticas do saneamento, na perspectiva da promoção da saúde e da prevenção de doenças.

Considera-se que conhecer tais discursos é algo relevante, ainda mais no momento presente, em que se desdobram discussões acerca do marco regulatório do saneamento, recém-instituído no Brasil.

Em sua primeira seção, este texto apresenta a metodologia utilizada para a apreensão dos discursos; a segunda apresenta os discursos apreendidos e a discussão correlata; a terceira e última seção compreende a conclusão do trabalho.

\section{METODOLOGIA}

Discursos, segundo Lefèvre e Lefevre (2005a), são a manifestação lingüística de um posicionamento a respeito de um dado tema. São formas de exprimir pensamentos, valores, crenças, representaçóes professadas pelos atores sociais a respeito dos eventos que cercam a vida.

Para os autores, o pensamento de uma coletividade, tanto quanto o pensamento individual, também constitui um discurso. $\mathrm{O}$ caminho metodológico que torna possível, mediante a utilização de procedimentos sistemáticos, controlados, padronizados e rigorosos, partir-se do pensamento individual como discurso para o pensamento coletivo como discurso é apresentado por meio da técnica do Discurso do Sujeito Coletivo - DSC (Lefèvre e Lefevre, 2005b).

Segundo Lefèvre e Lefèvre (2005b), os variados discursos coletivos que se pretende resgatar em uma pesquisa são reconstruídos a partir de expressões-chaves (ECHs). Estas são fragmentos de discursos individuais, trechos ou transcrições literais desses discursos, reveladoras da representação social do fenômeno em estudo.

Todo discurso tem uma ou mais idéias centrais (ICs). As idéias centrais são o sentido de cada discurso analisado e de cada conjunto homogêneo de $\mathrm{ECH}$, não se constituindo em interpretações, mas em descrições desse sentido.

No presente caso, para a construção dos discursos, foram selecionadas legislações de âmbito federal - vigentes ou ainda no formato de anteprojetos - relativas aos três setores envolvidos no estudo, totalizando seis textos.

Do setor saneamento foram abordados: 1) o Anteprojeto de Lei que propóe a Política Nacional de Resíduos Sólidos - PNRS, em discussão coordenada pelo Ministério do Meio Ambiente; e 2) a Lei 11.445/07 que estabelece as diretrizes nacionais para o saneamento básico e para a política federal de saneamento básico.

Do setor saúde os textos foram: 1) a Lei $8.080 / 90$ que dispõe sobre as condições para promoção, proteção e recuperação da saúde, a organização e o funcionamento dos serviços correspondentes; e 2) a Política Nacional de Promoção da Saúde - PNPS, decretada pelo Ministério da Saúde por meio da Portaria 687/06.

Do setor ambiente foram selecionados: 1) a Política Nacional de Meio Ambiente - PNMA, estabelecida pela Lei 6.938/81; e 2) a Política Nacional de Recursos Hídricos - PNRH, definida pela Lei 9.433/97.

Cada texto foi submetido à leitura minuciosa e exaustiva, a partir da qual foram identificados trechos que ofereciam resposta às perguntas a seguir relacionadas: 1) Que conceito de saneamento o texto apresenta?; 2) Que conceito de saúde o texto apresenta?; 3) Que conceito de ambiente o texto apresenta?; 4) Que objetivos o texto apresenta para as açōes de saneamento?; 5) Que referências o texto faz à sustentabilidade das açōes e benefícios do saneamento?; 6) Que referências o texto faz à articulação entre políticas, instituiçôes e açōes que envolvem o saneamento?; 7) Que referências o texto faz à participação técnica e não técnica nas ações de saneamento?; 8) Que referências o texto faz à educação sanitária e ambiental no âmbito das açōes de saneamento?; 9) Quem o texto apresenta como responsáveis pelas ações de saneamento?; e 10) Como o texto aborda a adaptabilidade das açôes de saneamento diante das características e peculiaridades do local onde as mesmas são realizadas e da população nele residente?
As respostas obtidas foram introduzidas no programa de informática Qualiquantisoft versão 1.3c, ferramenta que atua como organizador e tabulador dos dados que o pesquisador seleciona, facultando-lhe maior operacionalidade para a construção dos discursos.

Com o auxílio dessa ferramenta, foram resgatadas em sua literalidade as ECHs das respostas e, a partir daí, foram extraídas as ICs presentes nas mesmas. Na seqüência, foram agrupadas as ICs de mesmo sentido, sentido equivalente ou complementar, e elaborada uma ICsíntese para cada grupo criado.

Em seguida, para cada um dos grupos de ICsíntese, foram reunidas as ECHs correspondentes, as quais foram integradas de maneira a que formassem um texto, um discurso, constituindo um único DSC para cada agrupamento.

A partir da construção dos discursos relativos a cada grupo de ICsíntese, estes, por sua vez, foram examinados com base no referencial teórico da prevenção e da promoção, expostos em Souza e Freitas (2006).

O DSC 1 foi o único discurso identificado sobre o conceito de saneamento. Afirma, segundo a Lei 11445 , que o saneamento é composto por açôes e serviços exclusivamente de engenharia.

O termo saneamento é citado em todos os textos consultados, com exceção da PNMA, porém de modo que não foi possível identificar nenhuma outra conceituação clara a respeito que pudesse contribuir para a construção de outros discursos. Ou seja: o termo é tão-somente citado, mas não conceituado. É como se estivesse previamente claro o que esses textos desejam exprimir ao se reportarem a essa terminologia, não havendo necessidade de defini-la novamente.

Contudo, é evidente que há representações diferenciadas a respeito e, nesse sentido, o que mais chama a atenção é o anteprojeto da PNRS. Esse texto, ao citar saneamento, o faz apenas para destacar a importância da articulação entre a política de resíduos sólidos e a de saneamento. Não o conceitua, mas, por outro lado, deixa implícito que se trata de algo à parte, com o qual o manejo de resíduos sólidos não manteria nenhuma relação de pertencimento, contrariando aquilo que Moraes e Borja (2005) e Daltro Filho (2004), dentre outros autores, afirmam sobre as componentes do saneamento. 
Tabela I - Discurso do Sujeito Coletivo (DSC) sobre o conceito de saneamento

Saneamento é água, esgoto, lixo e drenagem

(Lei 11445-Art 2/III - Art 3/I/a,b,c,d)

\section{DSC 1}

Lei 11445-Art3/I/a,b,c,d Saneamento básico é o conjunto de serviços, infra-estruturas e instalaçôes operacionais de: a) abastecimento de água potável, constituido pelas atividades, infra-estruturas e instalaçóes necessárias ao abastecimento público de água potável, desde a captação até às ligaçôes prediais e respectivos instrumentos de medição; b) esgotamento sanitário, constituido pelas

atividades, infra-estruturas e instalaçôes operacionais de coleta, transporte, tratamento e disposição final adequados dos esgotos sanitários, desde as ligaçóes prediais até o seu lançamento final no meio ambiente; c) limpeza urbana e manejo de resíduos sólidos, conjunto de atividades, infra-estruturas e instalaçôes operacionais de coleta, transporte, transbordo, tratamento e destino final do lixo doméstico e do lixo originário da varrição e limpeza de logradouros e vias públicas; d) drenagem e manejo das águas pluviais urbanas, conjunto de atividades, infra-estruturas e instalações operacionais de drenagem urbana de águas pluviais, de transporte, detenção ou retenção para o amortecimento de vazões de cheias, tratamento e disposição final das águas pluviais drenadas nas áreas urbanas.

Tabela 2 - Discurso do Sujeito Coletivo (DSC) sobre o conceito de saúde

Saúde é uma produção social de determinação múltipla e complexa

(PNPS-p. 5,8 Lei 8080-Art 2/\$1-Art 3/caput/\$ único)

DSC 2

PNPS-p.5 A análise do processo saúde-adoecimento evidenciou que a saúde é resultado dos modos de organização da produção, do trabalho e da sociedade em determinado contexto histórico (...). Deve ser entendida PNPS-p.8 como produção social de determinação múltipla e complexa.

Lei 8080-Art2/\$1 O dever do Estado de garantir a saúde consiste na reformulação e execução de políticas econômicas e sociais que visem à redução de riscos de doenças e de outros agravos no estabelecimento de condições que assegurem acesso universal e igualitário às açôes e aos serviços para a sua promoção, proteção e recuperação.

Lei 8080- Art3/caput $A$ saúde tem como fatores determinantes e condicionantes, entre outros, a alimentação, a moradia, o saneamento básico, o meio ambiente, o trabalho, a renda, a educação, o transporte, o lazer e o acesso aos bens e serviços essenciais; os niveis de saúde da população expressam a organização social e econômica do País.

Lei 8080-Art3/Súnico Dizem respeito também à saúde as açōes que (...)se destinam a garantir às pessoas e à coletividade condiçôes de bem-estar físico, mental e social.

Os únicos textos que conceituam saúde são a PNPS e a Lei 8080 . No DSC 2, o conceito identificado define saúde, ou o estado de saúde de um indivíduo, como o "resultado dos modos de organização da produção, do trabalho e da sociedade"; uma "produção social de determinação múltipla e complexa”, ligada ao bem-estar físico, mental e social.

Esse conceito se mostra compatível com as idéias de Promoção da Saúde (PS), uma vez que se refere à saúde positiva e multidimensional. Resgata o discurso das legislaçóes do setor saúde, constituindo-se em um auto-conceito, o qual é influenciado pelo entendimento de que saúde não é mera ausência de doença.

Cabe aqui, entretanto, uma ressalva, que necessariamente deve ser feita: a enunciação de um conceito no âmbito de um texto legal não obrigatoriamente terá como resultado uma prática que o reproduza em sua essência. Por isso, embora o discurso conceitual aponte para a PS, a prática pode perfeitamente assumir um caráter preventivista. Daí porque Czeresnia (2003) afirma que a radicalidade da diferença entre PS e prevenção pode se confundir no seio das práticas exercidas, tal como explicitado em Souza e Freitas (2006).

Ainda sobre o conceito de saúde, embora este não tenha sido expresso pelos textos dos setores de saneamento e de ambiente, o termo saúde é por todos citado. Da mesma forma que para o termo saneamento, este fato sugere que o texto parte do princípio de que há uma conceituação - implícita - plenamente consolidada a respeito, à qual está sendo feita referência. Também nesse caso, contudo, há diversas representaçōes em jogo que necessariamente devem ser reveladas.

No DSC 3, elaborado a partir do ante-projeto da PNRS, o ambiente é apresentado como sendo constituído pelo "ar, o solo e as águas", ou seja o ambiente físico. Nessa mesma direção, assumindo um caráter estritamente ecológico, o DSC 4, delineando um auto-conceito de ambiente presente na PNMA, refere-se a um "conjunto de interaçōes físicas, químicas e biológicas”.
No DSC 5, a Lei 8080 apresenta um conceito de ambiente que também parece se reportar somente ao aspecto físico, ratificando, portanto, o conceito tradicional de ambiente, mas com uma diferença: insere nesse contexto ambientes não naturais, ou artificiais, como o ambiente de trabalho.

O conceito de ambiente não aparece claramente na Lei 11445 e nem na PNRH. Porém, é citado pelas mesmas como noção pré-estabelecida, como se não houvesse múltiplas representaçôes a respeito, da mesma forma como ocorre com os termos saneamento e saúde, como já referido.

Os DSCs 6 e 7 referem-se aos objetivos do saneamento. O DSC 6, construído a partir da Lei 11445 , apresenta o saneamento como fator propulsor do desenvolvimento nacional, na medida em que pode contribuir para a redução das desigualdades regionais, a geração de emprego e de renda e a inclusão social.

Esse discurso parece se aproximar de uma postura promocional, contudo, não se pode deixar de levar em conta 
que, para a Lei 11445 , o saneamento é um conjunto de serviços, infraestruturas e instalações operacionais (DSC 1). Portanto, é desse ponto de vista, exclusivamente como intervenção de engenharia, que aquela legislação vincula o saneamento ao desenvolvimento social.

O DSC 7, constituído pela Lei 11445, pelo anteprojeto da PNRS e pela PNPS, ao afirmar que o saneamento tem por objetivos proteger o meio ambiente e a saúde, parte do mesmo pressuposto conceitual sobre ambiente (presente nos DSCs 3 e 4).

Quanto ao conceito de saúde, há que se levar em conta que a PNRS e a PNPS compartilham esse DSC, cada uma, evidentemente, com o seu enfoque de saúde. No primeiro caso, a PNRS não estabelece o que entende por saúde. Se, entretanto, seguir a linha conceitual da Lei 11445 - o que é absolutamente pertinente por se tratar também de uma legislação de saneamento - estará se referindo a um conceito preventivista. Portanto, os objetivos do saneamento da mesma forma se coadunariam com esse enfoque. No segundo caso (como visto no DSC 2) a PNPS traz consigo um conceito promocional. Por extensão, os objetivos designados seriam marcados também por uma visão de PS. Esse DSC, em suma, apresenta caráter completamente ambíguo, aproximando-se tanto da prevenção quanto da promoção.

O DSC 8 aborda a sustentabilidade das ações de saneamento, mas sem se referir à duração dos benefícios - aspecto esse de total interesse desta pesquisa. Esse DSC, construído com base na Lei 11445 e no anteprojeto da PNRS, enfoca especificamente a sustentabilidade econômico-financeira dos serviços, o que pode se aproximar mais da prevenção ou se distanciar de qualquer enfoque de saúde, marcando seu caráter ambíguo.
De uma maneira geral, a sustentabilidade econômico-financeira das açōes deve ser uma preocupação permanente do saneamento promocional, assim como do preventivista, pois, do contrário, as ações poderão sofrer falhas de execução, operação e manutenção, afetando e comprometendo o caráter duradouro, ou mesmo temporário, dos benefícios gerados. Isto ocorrendo, a intervenção passaria a assumir uma natureza que não é nem promocional e nem preventivista. Nesse caso, estaria completamente desfigurada enquanto ação para a saúde, gerando tão-somente impactos negativos de variada ordem para esta, para o ambiente e para o Erário Público, em função do desperdício dos recursos humanos, materiais e financeiros empregados.

Contudo, considerando o DSC em questão, a preocupação com a sustentabilidade que se restringe aos aspectos econômico-financeiros como se es-

Tabela 3 - Discurso do Sujeito Coletivo (DSC) sobre o conceito de ambiente

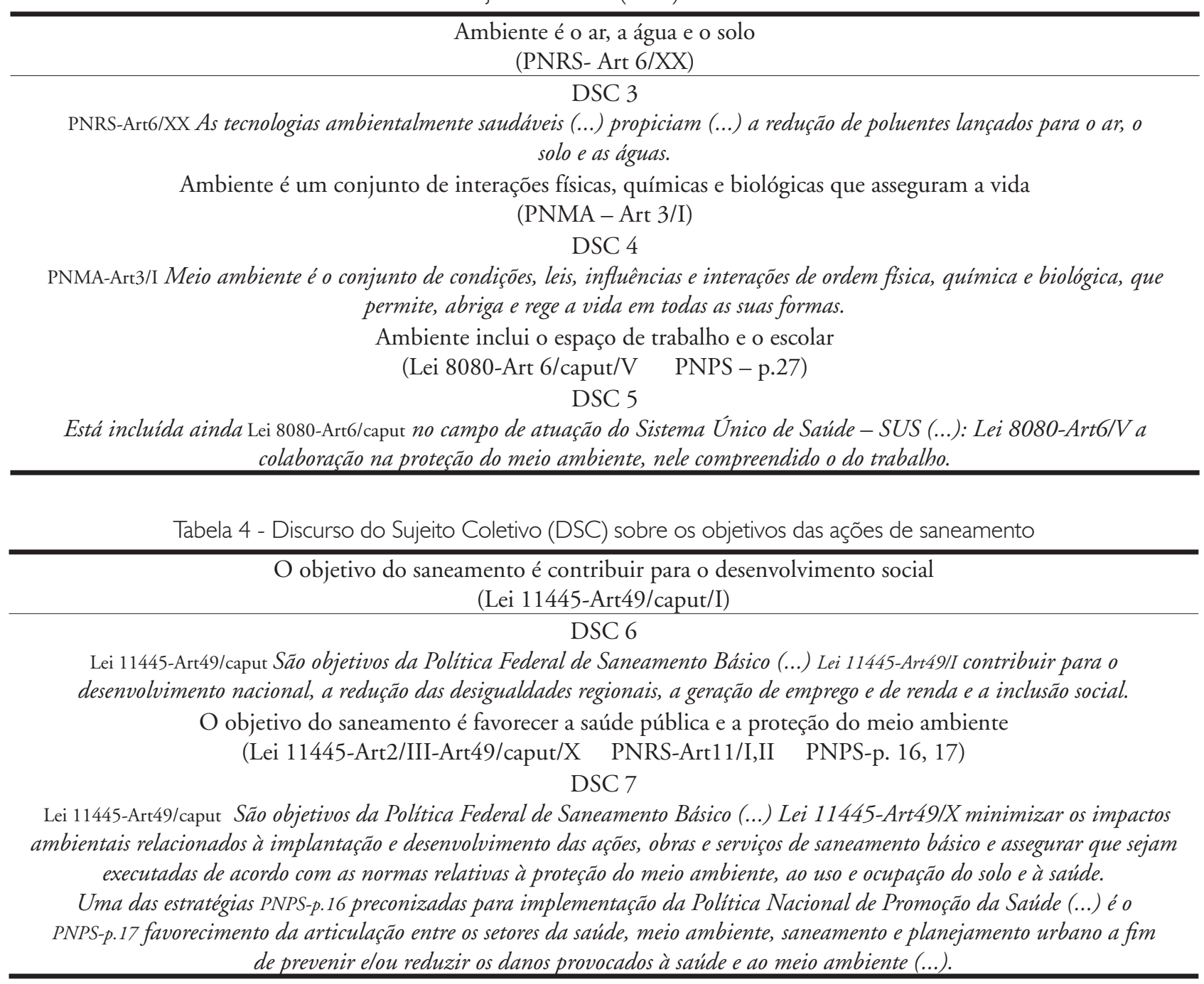


Tabela 5 - Discurso do Sujeito Coletivo (DSC) sobre a sustentabilidade das ações e benefícios do saneamento

A sustentabilidade econômico-financeira das ações de saneamento deve ser assegurada (Lei 11445-Art2/caput/VII-Art29/caput/I,II,III PNRS-Art3/X)

\section{DSC 8}

Lei 11445-Art2/caput Os serviços públicos de saneamento básico serão prestados tendo como um dos princípios fundamentais Lei 11445-Art2/VII a eficiência e a sustentabilidade econômica (...), Lei 11445-Art29/caput assegurada, sempre que possivel, mediante remuneração pela cobrança dos serviços (...).

tes, por si sós, fossem capazes de garantir a sustentabilidade da intervenção e de seus benefícios, deixando de considerar os determinantes sociais e a participação da população, está mais voltada para um enfoque preventivista.

Se, porém, tal preocupação for exacerbada, preponderante ou excludente, pode ser interpretada como a marca da lógica de mercado, dentro da qual o saneamento não é mais do que uma mercadoria que deve estar cotada a preços ótimos e cuja venda seja lucrativa. Nesse caso, essa visão, ainda que sob disfarces, em meio a possíveis subsídios tarifários, também não seria nem promocional e nem preventivista. Estaria, sim, totalmente fora de qualquer contexto de saúde, pois quem mais carece dos serviços de saneamento são, exatamente, cidadãos que nenhuma possibilidade dispóem para pagar os preços do capital.

Os DSCs 9 e 10 se reportam à articulação entre políticas, instituições e açóes que envolvem o saneamento. O DSC 9, presente no anteprojeto da PNRS, revela que a mesma é vista com importância pela legislação consultada, constituindo diretriz para o saneamento, com vistas a assegurar a exeqüibilidade dos serviços por meio da cooperação técnica e financeira.

O DSC 10, presente na Lei 8080 , na PNPS e na PNRH, destaca a articulação como diretriz para as ações e serviços que integram o SUS, a implementação da PNPS e da PNRH, favorecendo a saúde e o ambiente. Levando em conta o entendimento da Lei 8080 e da PNPS a respeito do conceito de saúde (DSC 2), parece evidente que o discurso pretende tratar a articulação como meio para a promoção da saúde e não para a prevenção de doenças. Quanto à PNRH, como a mesma não faz referência a um conceito de saúde, nada é possível afirmar sobre qualquer afiliação do discurso.

Contudo, é necessário lembrar que para a Lei 8080 e a PNPS, o conceito de ambiente se caracteriza, para- doxalmente, por um viés preventivista (DSC 5). Nessa mesma linha conceitual pode-se considerar que segue a PNRH, secundando a PNMA. Portanto, podese dizer que esse discurso é ambíguo, aproximando-se tanto da promoção quanto da prevenção.

O DSC 11, construído a partir do anteprojeto da PNRS e da Lei 11445 , refere-se à participação técnica e não técnica nas intervenções. Afirma que o controle social é um dos princípios dos serviços públicos de saneamento básico, tanto no que diz respeito às políticas, quanto às ações, desde a fase de formulação e planejamento, até a implementação e a fiscalização, cabendo aí, inclusive, a realização de audiências e consultas públicas.

O DSC 12 diz respeito à educação sanitária e ambiental no campo do saneamento, a partir das expressões contidas no anteprojeto da PNRS, como discurso de sujeito único. A percepção existente parece ser a de que se trata de uma ferramenta para ensinar a população alvo das açóes a se apropriar dos serviços de que passa a dispor.

A respeito da responsabilidade pelas ações, o DSC 13, com base na Lei 11445 e no anteprojeto da PNRS, afirma que o titular dos serviços é o responsável pela formulação de políticas, pela prestação dos serviços diretamente ou por delegação a outrem, assim como pela definição do ente regulador e fiscalizador. Essa é uma postura que, em si, não parece revelar nenhuma aproximação com a prevenção ou com a promoção, posto que apenas estabelece a existência de um ente responsável pelo setor. Mas, se conjugada com o DSC 11, que fala de controle social, pode ser considerada promocional.

Os DSCs 14, 15, 16 e 17 abordam as açóes de saneamento diante das características do local onde as intervenções são realizadas. O DSC 14, a partir das expressões da Lei 11445 , afirma que o saneamento deve ser adaptativo, buscando a conformidade de métodos, técnicas e processos com as características locais e regionais. Isto pode revelar uma aproximação com a visão preventivista, uma vez que o que parece estar no foco dessa adaptação são apenas os aspectos técnicos dos sistemas de engenharia.

O DSC 15, existente no anteprojeto da PNRS, destaca a inclusão dos catadores de lixo no fluxo de manejo dos resíduos sólidos. Essa proposição visa a contribuir para o bom funcionamento dos serviços, antes de mais nada. Porém, ao buscar também a inserção social de grupos de indivíduos que se fazem presentes em todo o território nacional, em geral exercendo sua atividade em meio às mais penosas condições de vida, sem dúvida poderá se aproximar das idéias promocionais.

O DSC 16, ao resgatar o discurso da Lei 11445, parece apresentar um saneamento promocional, capaz de adotar uma política tarifária inclusiva que lhe permita ser acessado por usuários que não disponham de condição econômica para pagar integralmente pelos serviços. Trata-se de um saneamento que realiza adaptações e contextualizações para além do aspecto técnico, assumindo uma postura de inclusão social.

O DSC 17, a partir da Lei 11445 , trata de um saneamento capaz de levar em conta aspectos sociais e culturais, especialmente para o atendimento de populações tradicionais, rurais e isoladas, o que o coloca também como uma ação promocional.

Analisando os discursos do ponto de vista de cada setor, a Tabela 11 apresenta os cinco discursos conceituais, segundo a legislação consultada.

Observa-se na Tabela 11 que, de uma maneira geral, o setor de saneamento não emite um conceito de saúde, mas refere-se a si próprio e ao ambiente dentro de um enfoque preventivista. $\mathrm{O}$ setor saúde, o único que apresenta os três conceitos em estudo, oferece um discurso considerado promocional sobre a saúde e preventivista sobre o saneamento e o ambiente, o que revela uma ambigüidade. $\mathrm{O}$ setor ambiente, por 
Tabela 6 - Discurso do Sujeito Coletivo (DSC) sobre a articulação das políticas, instituições e ações que envolvem o saneamento

A articulação é importante para a cooperação técnica e financeira

(PNRS-Art3/caput/VIII - Art7/caput)

\section{DSC 9}

PNRS-Art3/caput É uma diretriz geral aplicável aos residuos sólidos PNRS-Art3/VIII a articulação institucional entre as diferentes esferas do Poder Público, visando a cooperação técnica e financeira, especialmente nas áreas de meio ambiente, saneamento básico, saúde pública e educação.

A articulação é importante para a implementação das políticas e ações favorecendo a saúde e o ambiente (Lei 8080-Art6/II,V-Art7/caput/X-Art13/II-Art15/VII-Art16/II/a,b,c/IV PNPS-p.16,17 PNRH-Art31) DSC 10

Lei 8080 Art7/caput As açôes e serviços (...) que integram o Sistema Único de Saúde - SUS (...) obedecem ainda ao seguinte princípio: Lei 8080 Art7/X integração, em nível executivo, das ações de saúde, meio ambiente e saneamento básico.

Uma das estratégias PNPS-p.16 preconizadas para implementação da Política Nacional de Promoção da Saúde (...) é o PNPS-p.17 estímulo à criação de Rede Nacional de Experiências Exitosas na adesão e no desenvolvimento da estratégia de municipios saudáveis (...) com favorecimento da articulação entre os setores da saúde, meio ambiente, saneamento e planejamento urbano (...).

PNRH-Art31 Na implementação da Política Nacional de Recursos Hidricos, os Poderes Executivos do Distrito Federal e dos municípios promoverão a integração das políticas locais de saneamento básico, de uso, ocupação e conservação do solo e de meio ambiente com as politicas federal e estaduais de recursos hidricos.

Tabela 7 - Discurso do Sujeito Coletivo (DSC) sobre a participação técnica e não técnica nas ações de saneamento

A participação da sociedade é uma diretriz básica para as açôes de saneamento

(PNRS-Art10/IX Lei 11445-Art2/caput/X-Art3/IV-Art19/\$5-Art/27/I,II,III,IV-Art47/I,IV,V-Art51/\$único) DSC 11

Lei 11445-Art2/caput Os serviços públicos de saneamento básico serão prestados com base em princípios fundamentais tais como o Lei 11445-Art2/X controle social Lei 11445-Art3/IV (conjunto de mecanismos e procedimentos que garantem à sociedade informaçôes, representaçôes técnicas e participações nos processos de formulação de políticas, de planejamento e de avaliação relacionados aos serviços públicos de saneamento básico).

Lei 11445-Art19/\$5 Será assegurada ampla divulgação das propostas dos planos de saneamento básico e dos estudos que as fundamentem, inclusive com a realização de audiências ou consultas públicas.

Tabela 8 - Discurso do Sujeito Coletivo (DSC) sobre a educação sanitária e ambiental no âmbito das ações de saneamento

Educação sanitária e ambiental para promover mudança/incorporação de hábitos

(PNRS-Art3/VI)

DSC 12

PNRS-Art3/VI Uma das diretrizes gerais aplicáveis aos residuos sólidos é a promoção de campanhas informativas e educativas sobre a produção e o manuseio de residuos sólidos e sobre os impactos negativos que os resíduos sólidos causam ao meio ambiente, à saúde e à economia.

Tabela 9 - Discurso do Sujeito Coletivo (DSC) sobre a responsabilidade pelas ações de saneamento

O responsável é o titular

(Lei 11445-Art8-Art9/caput/II PNRS-Art16/caput)

DSC 13

Lei 11445-Art9/caput $O$ titular dos serviços formulará a respectiva política pública de saneamento básico, devendo, para tanto, Lei 11445-Art9/II prestar diretamente ou autorizar a delegação dos serviços e definir o ente responsável pela sua regulação e fiscalização, bem como os procedimentos de sua atuação. 
Tabela 10 - Discurso do Sujeito Coletivo (DSC) sobre a adaptabilidade das ações de saneamento diante das características e peculiaridades locais

Adaptação às características físicas e antrópicas locais (Lei 11445-Art. 2/caput/V/VIII)

\section{DSC 14}

Lei 11445-Art.2/caput Os serviços públicos de saneamento básico serão prestados com base em princípios fundamentais tais como Lei 11445-Art.2/V a adoção de métodos, técnicas e processos que considerem as peculiaridades locais e regionais; Lei 11445-Art.2/VIII a utilização de tecnologias apropriadas, considerando a capacidade de pagamento dos usuários e a adoção de soluçôes graduais e progressivas.

Inserção social dos catadores ao serviço

\section{(PNRS-Art10/XIV)}

\section{DSC 15}

PNRS-Art10/XIV São diretrizes para os serviços públicos de manejo dos resíduos sólidos o incentivo e a promoção da inserção social dos catadores de materiais recicláveis, mediante apoio à sua organização em associaçôes ou em cooperativas de trabalho (...).

Subsídios aos usuários que não podem pagar integralmente

$$
\text { (Lei 11445-Art29/\$1/ I,II/ \$2) }
$$

DSC 16

Lei 11445-Art29/\$1 A instituição das tarifas, preços públicos e taxas para os serviços de saneamento básico observará as seguintes diretrizes: Lei 11445-Art29/\$1/I prioridade para atendimento das funções essenciais relacionadas à saúde pública; Lei 11445-Art29/\$1/II ampliação do acesso dos cidadãos e localidades de baixa renda aos serviços.

Lei 11445-Art29/\$2 Poderão ser adotados subsídios tarifários e não tarifários para os usuários e localidades que não tenham capacidade de pagamento ou escala econômica suficiente para cobrir o custo integral dos serviços.

Atendimento às comunidades isoladas e minorias rurais e urbanas

$$
\text { (Lei 11445-Art48/caput/VII-Art49/III,IV) }
$$

\section{DSC 17}

Lei 11445-Art48/caput $A$ Uniāo, no estabelecimento de sua política de saneamento básico, observará diretrizes tais como Lei 11445-Art48/VII a garantia de meios adequados para o atendimento da populaçāo rural dispersa, inclusive mediante a utilização de soluçôes compativeis com suas características econômicas e sociais peculiares; (...) Lei 11445-Art49/III proporcionará condiçôes adequadas de salubridade ambiental aos povos indígenas e outras populaçôes tradicionais, com soluçôes compativeis com suas características sócio-culturais.

\begin{tabular}{|c|c|c|c|c|}
\hline \multicolumn{2}{|c|}{ Legislação } & \multirow{2}{*}{$\frac{\text { Conceito }}{\text { Saneamento }}$} & \multirow{2}{*}{$\begin{array}{c}\text { Carater } \\
\text { Preventivista }\end{array}$} & \multirow{2}{*}{$\frac{\text { DSC de referência }}{1}$} \\
\hline Setor Saneamento & Lei 11445 & & & \\
\hline & & Saúde & - & - \\
\hline & & Ambiente & - & - \\
\hline & PNRS & Saneamento & - & - \\
\hline & & Saúde & - & - \\
\hline & & Ambiente & Preventivista & 3 \\
\hline \multirow[t]{6}{*}{ Setor Saúde } & PNPS & Saneamento & - & - \\
\hline & & Saúde & Promocional & 2 \\
\hline & & Ambiente & Preventivista & 5 \\
\hline & Lei 8080 & Saneamento & - & - \\
\hline & & Saúde & Promocional & 2 \\
\hline & & Ambiente & Preventivista & 5 \\
\hline \multirow[t]{6}{*}{ Setor Ambiente } & PNMA & Saneamento & - & - \\
\hline & & Saúde & - & - \\
\hline & & Ambiente & Preventivista & 4 \\
\hline & PNRH & Saneamento & - & - \\
\hline & & Saúde & - & - \\
\hline & & Ambiente & - & - \\
\hline
\end{tabular}

Tabela II - Conceitos presentes nos discursos identificados 
sua vez, não oferece nenhum discurso sobre saúde e saneamento, limitando-se apenas a um conceito de ambiente que apresenta viés preventivista.

O ambiente é o único conceito trabalhado pelos três setores dentro de uma visão unanimemente preventivista. A saúde e o saneamento somente receberam conceitos em suas próprias legislaçôes setoriais.

Quanto aos discursos relativos às práticas do saneamento, analisando-se do ponto de vista de cada setor, a Lei 11445 e o anteprojeto da PNRS, pelo setor saneamento, são os textos que mais contribuíram para os DSCs, conforme mostra a Tabela 12. Pelo que se pode observar, o caráter dos discursos é bastante variado. Há discursos promocionais, preventivistas e ambíguos. Além disso, há, também, omissões discursivas.

Pelo setor saúde, as contribuiçôes da PNPS e da Lei 8080 ocorreram em menor número, sendo quase todas oriundas do primeiro texto. Além das omissões discursivas, predominantes no setor, há dois discursos ambíguos, um quanto aos objetivos das ações (DSC 7), e um outro relativo à articulação entre políticas, instituições e ações (DSC 10).
Finalmente, pelo setor ambiente, não houve contribuições, a não ser uma única extraída da PNRH quanto à articulação entre políticas, instituições e açoes (DSC 10), a qual, contudo, é ambígua, pois não aponta claramente nem para a prevençáo e nem para a PS.

\section{CONCLUSÃO}

A legislação consultada e analisada revelou pensamentos, valores e representaçôes sociais importantes de serem consideradas sobre os conceitos e as diretrizes práticas que envolvem o setor saneamento na sua relação com os setores saúde e ambiente.

Revelou a predominância de conceitos preventivistas; a predominância de diretrizes práticas promocionais; a existência de visões ambíguas dentro de uma mesma legislação, assim como de um mesmo discurso; a ocorrência de omissōes discursivas.

A predominância de discursos reveladores de conceitos preventivistas nos setores de saneamento e de ambiente e na Lei 8080 , pelo setor saúde, sugere o quanto, do ponto de vista legal, esses setores ainda estão centrados em pressupostos limitados que, por essa razão, se ajustam com dificuldade ao contexto do mundo atual.
No que diz respeito às práticas, mesmo a predominância de discursos promocionais sobre os preventivistas deve ser encarada com cuidado, pois como ressalta Czeresnia (2003), as prescrições teóricas podem não resultar na organização de práticas concretas em torno de si, que confirmem seu caráter essencial. Isto quer dizer que não é possível afirmar que os citados discursos promocionais se convertam em ações de fato promocionais, no cotidiano dos profissionais envolvidos na relação saneamento-saúde-ambiente.

Nesse sentido, é importante também observar que a quantidade de visōes ambíguas e de omissões identificadas, tanto em relação aos conceitos quanto às diretrizes práticas, provavelmente - para não dizer com toda a certeza - acaba por comprometer o estabelecimento do predomínio dos discursos promocionais, tornando dominantes as práticas preventivistas.

Essas ambigüidades também podem revelar que discursos estão sendo utilizados para expressar conceitos que não estão claros, que se misturam e confundem. Por outro lado, podem ainda representar um avanço, pois indicam que, de alguma forma, os conceitos em questão começam a ser envolvidos por

Tabela 12 - Caráter das práticas identificadas nos discursos do setor saneamento

\begin{tabular}{|c|c|c|c|}
\hline Legislação & Categoria & Caráter & DSC de referência \\
\hline \multirow[t]{7}{*}{ Lei 11445} & Objetivos das ações & Preventivista & 6 e 7 \\
\hline & Preocupação quanto à sustentabilidade das ações & Ambíguo & $\begin{array}{l}8 \text { (preventivista/nem } \\
\text { preventivista e nem } \\
\text { promocional) }\end{array}$ \\
\hline & Articulação entre políticas, instituições e ações & - & - \\
\hline & Modelo de intervenção (participação técnica e não técnica) & Promocional & 11 \\
\hline & Estratégias (educação sanitária e ambiental) & - & - \\
\hline & Executores dos projetos (responsabilidade pelas açôes) & Promocional & 13 \\
\hline & Modelo de gestão (adaptabilidade das ações) & Ambíguo & $\begin{array}{c}14 \text { (preventivista), } 16 \text { e } \\
17 \text { (promocionais) }\end{array}$ \\
\hline \multirow[t]{7}{*}{ PNRS } & Objetivos das ações & Preventivista & 7 \\
\hline & Preocupação quanto à sustentabilidade das ações & Ambíguo & $\begin{array}{l}8 \text { (preventivista/ nem } \\
\text { preventivista e nem } \\
\text { promocional) }\end{array}$ \\
\hline & Articulação entre políticas, instituições e ações & Preventivista & 9 \\
\hline & Modelo de intervenção (participação técnica e não técnica) & Promocional & 11 \\
\hline & Estratégias (educação sanitária e ambiental) & Preventivista & 12 \\
\hline & Executores dos projetos (responsabilidade pelas ações) & Promocional & 13 \\
\hline & Modelo de gestão (adaptabilidade das ações) & Promocional & 15 \\
\hline
\end{tabular}


um movimento de ampliação, no qual percepções tradicionais são revisitadas por novas idéias, fundamentando-se em novos paradigmas.

Quanto às omissôes conceituais, marcantes nos setores de saneamento e, principalmente, no de ambiente, podem sugerir um outro sintoma da limitação do olhar desses setores, uma vez que parecem considerar plena e definitivamente estabelecidos os conceitos em questão, reportando-se a eles, sem emitir sua própria visão, como se não houvesse uma diversidade de representaçôes a respeito.

Se há ambigüidades e omissões nos discursos conceituais, isto pode significar que práticas, também indefinidas e desencontradas, estão sendo propostas pela legislação consultada sobre tal base conceitual, o que pode sinalizar para uma grande falta de clareza no diálogo entre os setores envolvidos, para o conflito de diferentes visōes que buscam se tornar hegemônicas, ou mesmo para ambos.

Sendo assim, buscar o caminho da discussão intersetorial, da convergência de interesses e da realização de ações conjuntas parece claramente necessário para o avanço de conceitos e práticas e $\mathrm{o}$ fortalecimento da relação saneamentosaúde-ambiente.

Nesse sentido, a Promoção da Saúde, como suporte teórico-prático para as ações, conforme discutido em Souza e Freitas (2006), pode ser considerada significativamente capaz de conduzir o saneamento ao êxito que uma sociedade complexa e democrática demanda e espera.

\section{AGRADECIMENTOS}

O presente trabalho foi realizado com apoio do CNPq - Conselho Nacional de Desenvolvimento Científico e Tecnológico (Brasil).

\section{REFERÊNCIAS}

ANTEPROJETO DE LEI DA POLÍTICA NACIONAL DE RESÍDUOS SÓLIDOS. Disponível em: www.mma.gov.br/port/sqa/residuos. Acesso em: 16 jun. 2006

CZERESNIA, D. O conceito de saúde e a diferença entre prevenção e promoção. In: CZERESNIA, D.; FREITAS, C.M. (Orgs.). Promoção da Saúde: conceitos, reflexôes, tendências. Rio de Janeiro: Editora Fiocruz, p. 39-53. 2003.

CZERESNIA, D.; FREITAS, C.M. (Orgs.). Promoção da Saúde: conceitos, reflexōes, tendências. Rio de Janeiro: FIOCRUZ, 176p. 2003.

DALTRO FILHO, J. Saneamento ambiental: doença, saúde e o saneamento da água. São Cristóvão: Editora UFS; Aracaju: Fundação Oviêdo Teixeira, 332p. 2004.

LEFÈVRE, F.; LEFÈVRE, A.M.C. Promoção de saúde: a negação da negação. Rio de Janeiro: Vieira \& Lent, 166p. 2004.

LEFÈVRE, F; LEFÈVRE, A.M.C. Depoimentos e discursos: uma proposta de análise em pesquisa social. Brasília: Líber Livro Editora, 97p. 2005a.

LEFÈVRE, F; LEFÈVRE, A.M.C. $O$ discurso do sujeito coletivo: um novo enfoque em pesquisa qualitativa (desdobramentos). 2 ed. Caxias do Sul: Educs, 256p. 2005b.

LEI 11.445/07. Disponível em: https://www.planalto.gov.br/ccivil. Acesso em: 15 mai. 2007.

LEI 6.938/81. Disponível em: www.planalto.gov. br/casacivil. Acesso em: 16 jun. 2006.

LEI 8.080/90. Disponível em: www.saude.gov. br/legislação. Acesso em: 12 jul. 2006.
LEI 9.433/97. Disponível em: www.planalto.gov. br/casacivil. Acesso em: 16 jun. 2006.

MORAES, L.R.S.; BORJA, P.C. Política e Plano Municipal de Saneamento Ambiental: experiências e recomendaçōes. Brasília: Organização PanAmericana da Saúde; Ministério das Cidades, 141p. 2005.

POLÍTICA NACIONAL DE PROMOÇÃO DA SAÚDE. Disponível em: www.portal.saude. gov.br/portal. Acesso em: 16 jun. 2006.

SOUZA, C.M.N.; FREITAS, C.M. O saneamento na ótica da prevenção de doenças e da promoção da saúde. In: XXX CONGRESO INTERAMERICANO DE INGENIERIA SANITÁRIA Y AMBIENTAL. Punta del Leste. Anais Eletrônicos. Punta del Leste: AIDIS, 2006.

STATCHENKO, S.; JENICECK, M. Conceptual differences between prevention and health promotion: research implications for community health programs. Canadian Journal of Public Health, v. 81 , p. $53-59,1990$.

TEIXEIRA, C. O futuro da prevenção. Salvador, BA: Casa da Qualidade Editora, 115p. 2001.

Endereço para correspondência:

Cezarina Maria Nobre Souza

Rua Aguiar, 47/406 Tijuca

2026 I- I 20 Rio de Janeiro - RJ

- Brasil

Telefax: (2I) 3234-5 I 40

E-mail: cezarina.souza@oi.com.br 